\title{
Thermal Degradation Behavior of Epoxy Resin Blended with Propyl Ester Phosphazene
}

\author{
BAR-LONG DENQ, ${ }^{1, *}$ WEN-YEN CHIU, ${ }^{1}$ KING-FU LIN, ${ }^{1}$ MING-REN STEVE FUH ${ }^{2}$ \\ ${ }^{1}$ Institute of Material Science and Engineering, National Taiwan University, Taipei, Republic of China \\ ${ }^{2}$ Department of Chemical, Soochow University, Taipei, Republic of China
}

Received 23 June 2000; accepted 3 December 2000

\begin{abstract}
The study was focused on the thermal degradation behavior of epoxy resins (EP) blended with propyl ester phosphazene (FR). The analysis studied the evolved gas and the residual char yield using different techniques. The results showed that pure epoxy resin and their blends were all a one-stage thermal degradation reaction. The major degradation temperature of blends was lower than the temperature of pure epoxy resin, but the residual char yield of epoxy blends at $550^{\circ} \mathrm{C}$ was higher than that of pure epoxy resin. FR could accelerate the production of small molecules such as acetone, phenol, and isopropyl phenol during thermal degradation process. Honeycomb structure compounds were also formed in the residual char of epoxy and its blends. Additionally, elemental analysis of the residual char yield showed that phosphorus was a residual element, and other elements mostly diffused to the evolved gas. (C) 2001 John Wiley \& Sons, Inc. J Appl Polym Sci 81: 1161-1174, 2001
\end{abstract}

Key words: blends; epoxy resin; propyl ester phosphazene; pyrolysis mechanism; thermal degradation

\section{INTRODUCTION}

Due to the excellent mechanical properties and adhesion, epoxy resins are widely used in aerospace and other fields. Although they have excellent chemical and mechanical properties, they are not stable at high temperatures. Many studies about thermal degradation of epoxy resin had been reported. For example, Grassie et al. ${ }^{1}$ had used the subambient thermal volatilization analysis procedure (SATVA) to examine the products

\footnotetext{
Correspondence to: B. L. Denq (860768@itri.org.tw).

* Present address: Industrial Technology Research Institute, Material Research Laboratory, Chutung, Hsinchu, Taiwan 310, R.O.C.

Contract grant sponsor: Chung Shan Institute of Science and Technology.

Journal of Applied Polymer Science, Vol. 81, 1161-1174 (2001)

(C) 2001 John Wiley \& Sons, Inc.
}

evolved during the thermal degradation of epoxy resin, and proposed the thermal degradation mechanism from the viewpoint of the bond energy. They suggested that because oxygen and nitrogen atoms have greater negative inductive effect than other atoms, the scission of epoxy resin would take place at $\mathrm{O}-\mathrm{CH}_{2}$ and $\mathrm{C}-\mathrm{N}$ bonds to form phenol, amine, and other small related molecules. Bellenger et al. ${ }^{2}$ had studied the thermal degradation behavior of diglycidyl ether bisphenol A (DGEBA) and tetraglycidyl methylene dianiline (TGMDA) epoxy prepolymer cured with different amines such as diethylene triamine (DETA), iso-phorone diamine (IPD), diamino diphenyl sulphone (DDS), and diamino diphenyl ether (DDE) under the oxidative and nonoxidative conditions. The thermal degradation mechanism was influenced by the curing agents, amine concentration, and the nitrogen atom nu- 
cleophilicity. Recently, many literatures ${ }^{3-5}$ have reported that phosphorus-containing compounds can be used as additives to improve the thermal stability of many polymers besides epoxy resins. For example, Denq et al. ${ }^{5}$ reported propyl ester phosphazene, used as a flame retardant with high phosphorous and nitrogen content, would react with PMMA to form an anhydride structure that could increase the major thermal degradation temperature. Other reports ${ }^{6,7}$ have point out that phosphorus-containing compounds would form phosphorus-like acid structure during the thermal degradation. The function of phosphorus-like acid was stated as follows:

1. Cyclic structures ${ }^{6}$ were formed by dehydration, and by further degradation they could break into a variety of small molecules.

2. Free radicals ${ }^{6,7}$ in the gas phase were captured by the phosphorus-like acid. Both the volatile and combustible gases on the surface were insulated by the formed carbonaceous char to stop the further thermal degradation.

3. Epoxy resins ${ }^{7}$ blended with organophosphonic compounds containing phosphorus, chloride, or nitrogen would produce nonvolatile residuals during the thermal degradation. These nonvolatile residuals could form thermostable structures with aromatic $\mathrm{C}-\mathrm{Cl}$ and $\mathrm{P}=\mathrm{N}$ bonds.

In our previous study, ${ }^{8}$ the curing kinetics and physical properties of epoxy resins (DGEBA/ DETA) were deeply influenced by the FR content. The detailed studies on the thermal degradation of epoxy resins blended with FR have been not yet reported, and therefore, we investigated it using different analytical techniques in this study.

Table I Composition and Phosphorus Content of Blended Samples

\begin{tabular}{llcc}
\hline & \multicolumn{1}{c}{ Weight Ratio } \\
Code & $($ DGEBA/DETA/FR $)$ & $P($ wt \%) & $P(\text { wt } \%)^{\mathrm{b}}$ \\
\hline Ep0f & $89.37: 10.63: 0$ & 0.00 & $<0.01$ \\
Ep1f & $82.04: 9.75: 8.21$ & 1.91 & 1.86 \\
Ep2f & $75.82: 9.02: 15.16$ & 3.50 & 3.47 \\
FR & $0: 0: 100$ & 21.0 & 21.0 \\
\hline
\end{tabular}

${ }^{\text {a }}$ Phosphorus content from composition calculation.

${ }^{\mathrm{b}}$ Phosphorus content by the colorimeter. ${ }^{10}$

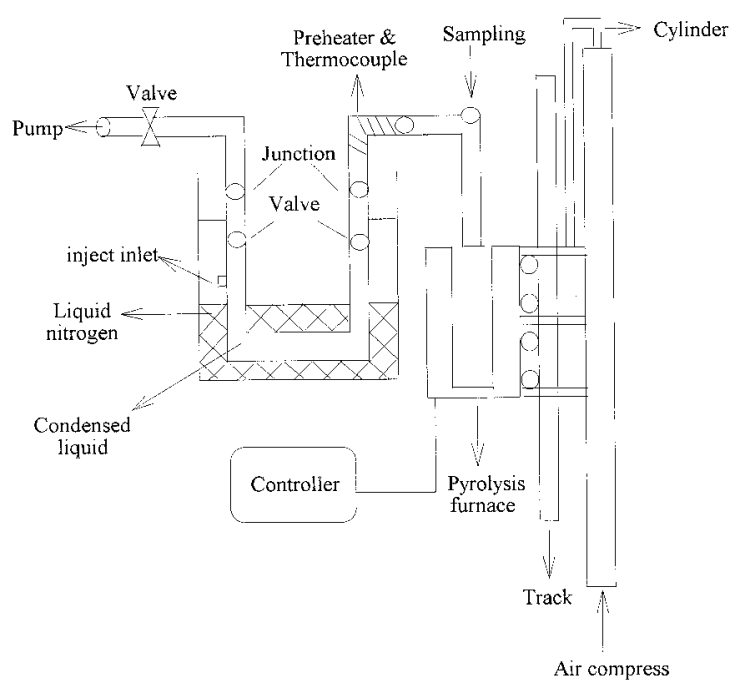

Figure 1 The scheme of apparatus used to degrade and collect volatile products.

\section{EXPERIMENTAL}

\section{Materials}

The epoxy prepolymer used in this study was diglycidyl ether bisphenol A (DGEBA) (DER 331, from Dow Chemical Company) with a molecular mass of $380 \mathrm{~g} / \mathrm{mol}$ (epoxide equivalent weight ${ }^{9}$ of $190 \mathrm{~g} / \mathrm{Eq})$. A stoichiometeric amount of diethylenetriamine (DETA, from Janssen Chimica Company) with a molecular mass of $103.15 \mathrm{~g} / \mathrm{mol}$ (amine equivalent weight of $20.63 \mathrm{~g} / \mathrm{Eq}$ ) was used as a curing agent. Propyl ester phosphazene (FR) was supplied by Chung Shan Institute of Science and Technology. The chemical structure of these materials are shown below:
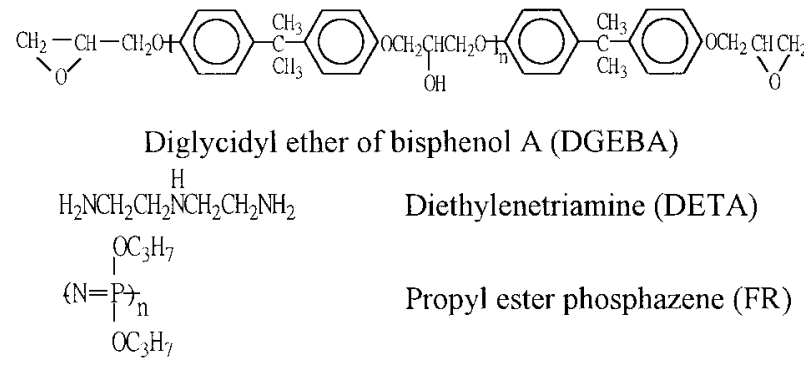

The formulations of epoxy blended with various amount of FR were shown in Table I and were referred as Ep0f, Ep1f, and Ep2f, respectively. The cure cycle of samples was: precure temperature of $75^{\circ} \mathrm{C}$ for $2 \mathrm{~h}$ and postcure temperature of $95^{\circ} \mathrm{C}$ for $1 \mathrm{~h}$ under atmosphere. 


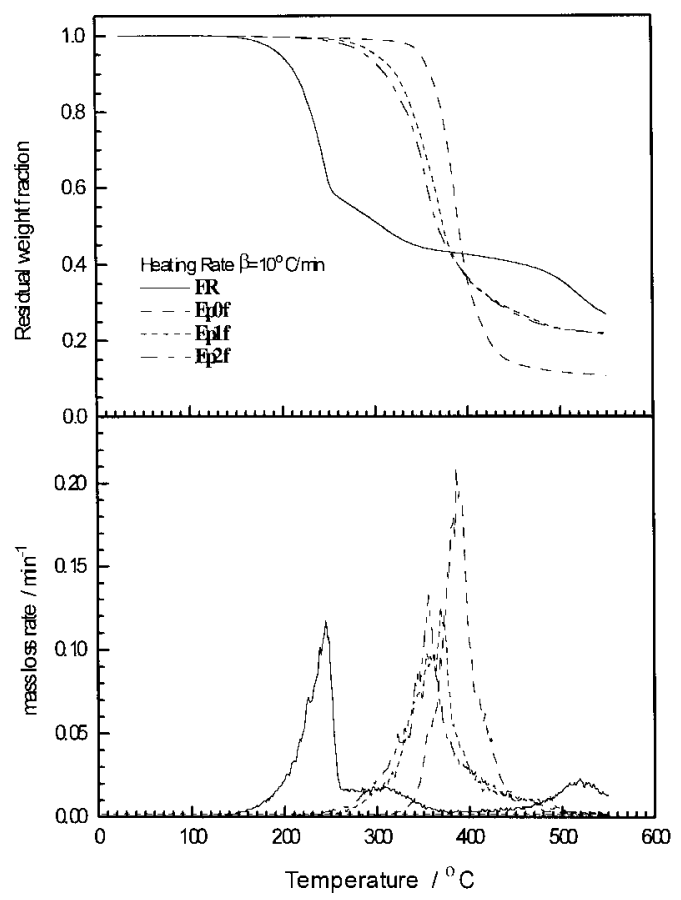

Figure 2 TG-DTG thermograms of FR and epoxy blends at a heating rate of $10^{\circ} \mathrm{C} / \mathrm{min}$ under nitrogen atmosphere.

\section{METHODS}

\section{Thermal Degradation}

The thermal degradation was examined by a Perkin-Elmer TGA-7 thermogravimetric analysis (TGA) at the heating rate of $10^{\circ} \mathrm{C} / \mathrm{min}$ under a nitrogen atmosphere with a flow rate of $40 \mathrm{~mL} /$ $\min$.

\section{Analysis of Evolved Gas}

\section{Method 1: TGA/FTIR}

The gas products of degraded epoxy blends were investigated using a SEIKO SSC 5000 thermo-

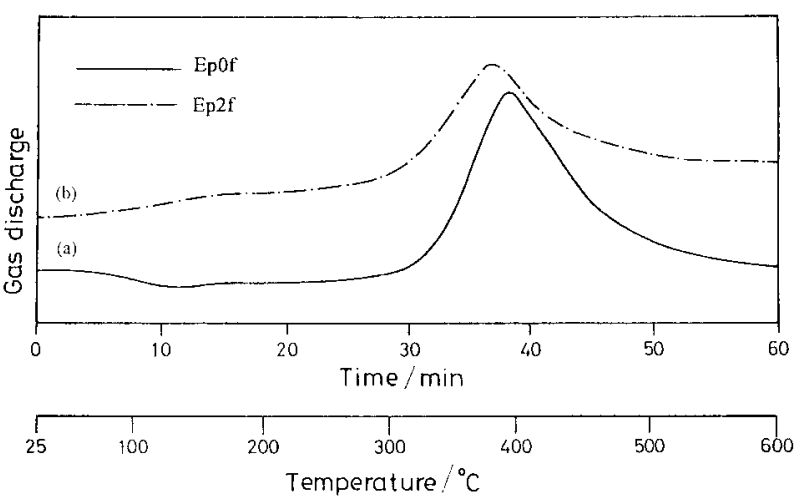

Figure 3 The gas discharge with time (temperature) during thermal degradation for (a) Ep0f and (b) Ep2f at a heating rate of $10^{\circ} \mathrm{C} / \mathrm{min}$.

gravimetric analysis coupled with a BIO-RAD FTS-40 Fourier transform infrared spectrometer (TGA-FTIR). Samples were heated at a heating rate of $10^{\circ} \mathrm{C} / \mathrm{min}$ under a nitrogen atmosphere with a flow rate of $40 \mathrm{~mL} / \mathrm{min}$. The FTIR spectra were identified by visual analysis and by searching the spectral data bases.

\section{Method 2: Pyrolysis/GC/MS}

The gas products during the degradation of epoxy blends, about $600 \mu \mathrm{g}$, at various temperatures were investigated using a pyrolyzer (Gas pyroprobe CDS-2000) coupled with a gas chromatography (Hewlett-Packard 5890 series II) equipped with a thermal conductivity detector (TCD), and a capillary column (Hewlett-Packard HP-5, $30 \mathrm{~m}$ long $\times 0.25 \mathrm{~mm}$ i.d. coated with the crosslinking packing of 5\% diphenyl and $95 \%$ diphenyl polysiloxane). The heating rate was set to $200^{\circ} \mathrm{C} / \mathrm{ms}$ in these experiments. The GC conditions were designed to separate the pyrolysis products based on their boiling points and was operated under the following operating parameters: the column

Table II Characteristics of Thermal Degradation of Various Blends at Heating Rate of $10^{\circ} \mathrm{C} / \mathrm{min}$

\begin{tabular}{|c|c|c|c|c|c|}
\hline \multirow[b]{2}{*}{ Blends } & \multirow[b]{2}{*}{$T_{5 \%} /{ }^{\circ} \mathrm{C}$} & \multirow{2}{*}{$\begin{array}{l}\% \text { Residual } \\
\text { at } 550^{\circ} \mathrm{C}\end{array}$} & \multicolumn{3}{|c|}{ Temperature Range $/{ }^{\circ} \mathrm{C}$} \\
\hline & & & Stage 1 & Stage 2 & Stage 3 \\
\hline FR & 224.98 & 37.47 & $140-268$ & $271-340$ & $340-550$ \\
\hline Ep0f & 351 & 14.6 & - & $317-550^{\mathrm{a}}$ & - \\
\hline Ep1f & 302 & 23.9 & - & $250-550^{\mathrm{a}}$ & - \\
\hline Ep2f & 291 & 24.3 & - & $231-550^{\mathrm{a}}$ & - \\
\hline
\end{tabular}

a The major degradation temperature of epoxy or its blends is located in the second stage degradation of FR. 

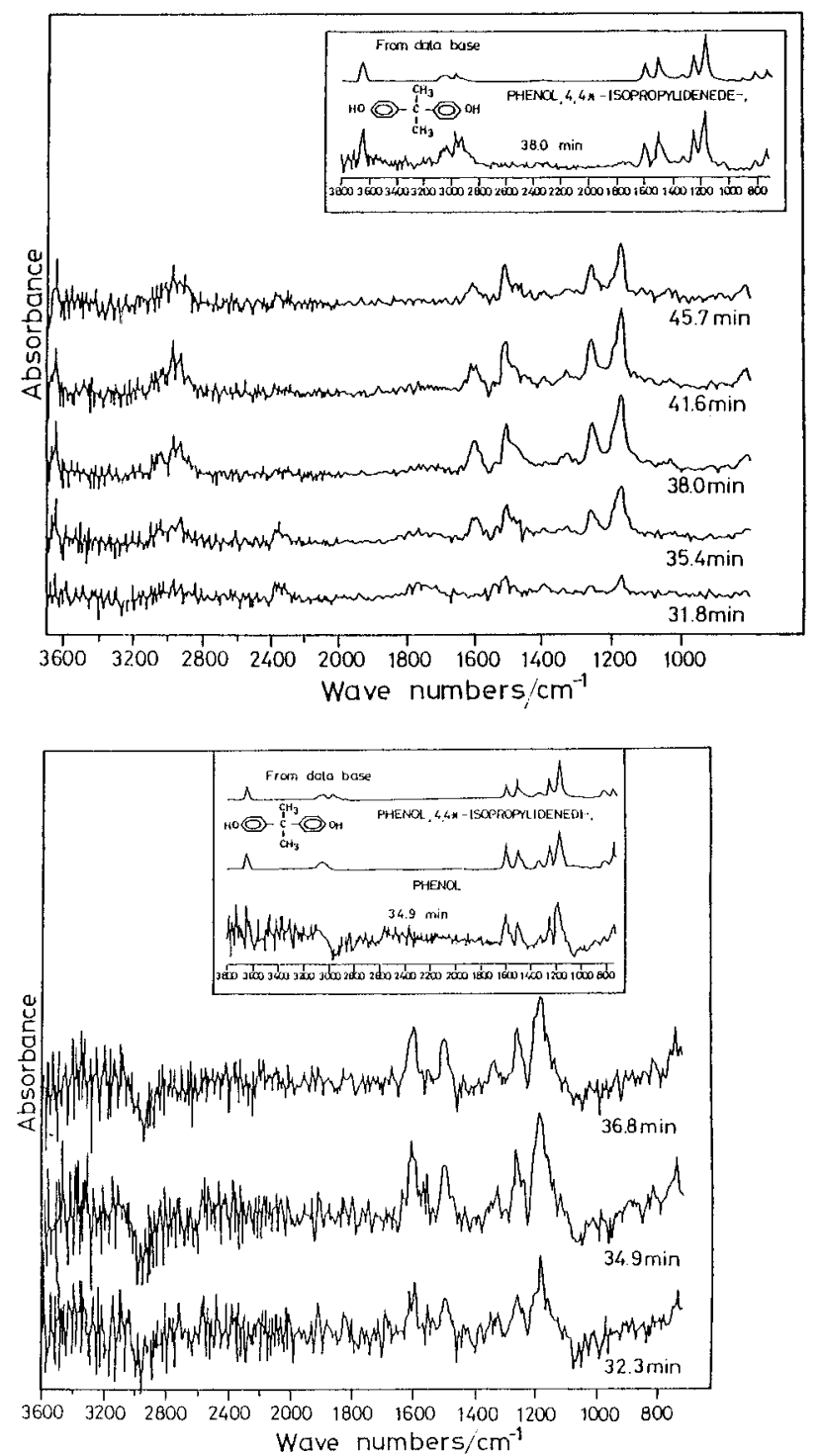

Figure 4 FTIR spectra of gas phase evolved at various thermal degradation time for (a) Ep0f and (b) Ep2f.

injection temperature was set to $220^{\circ} \mathrm{C}$; the column operated isothermally at $40^{\circ} \mathrm{C}$ for $2 \mathrm{~min}$ and then heated to $220^{\circ} \mathrm{C}$ at the heating rate of $10^{\circ} \mathrm{C} /$ min; the carrier gas was helium with a flow rate of $50 \mathrm{~mL} / \mathrm{min}$. The spectra of the evolved gases were identified using a mass detector (Hewlett-Packard 5971) with the scanning range of $m / e$ from 30 to 400 operated at $70 \mathrm{eV}$, and compared with the spectral databases and literature..$^{1,11,12}$

\section{Method 3: Separation/GC/MS}

Thermal degradation of epoxy resins was carried out in the apparatus shown in Figure 1. The powdered sample, of about $8 \mathrm{~g}$ mass, was put in the
T-shape tube and heated to certain temperature with the heating rate of $10^{\circ} \mathrm{C} / \mathrm{min}$ under vacuum. The gases, evolved during degradation, were divided into three types: (i) products with boiling point lower than liquid nitrogen temperature, which remained in the gas state under liquid
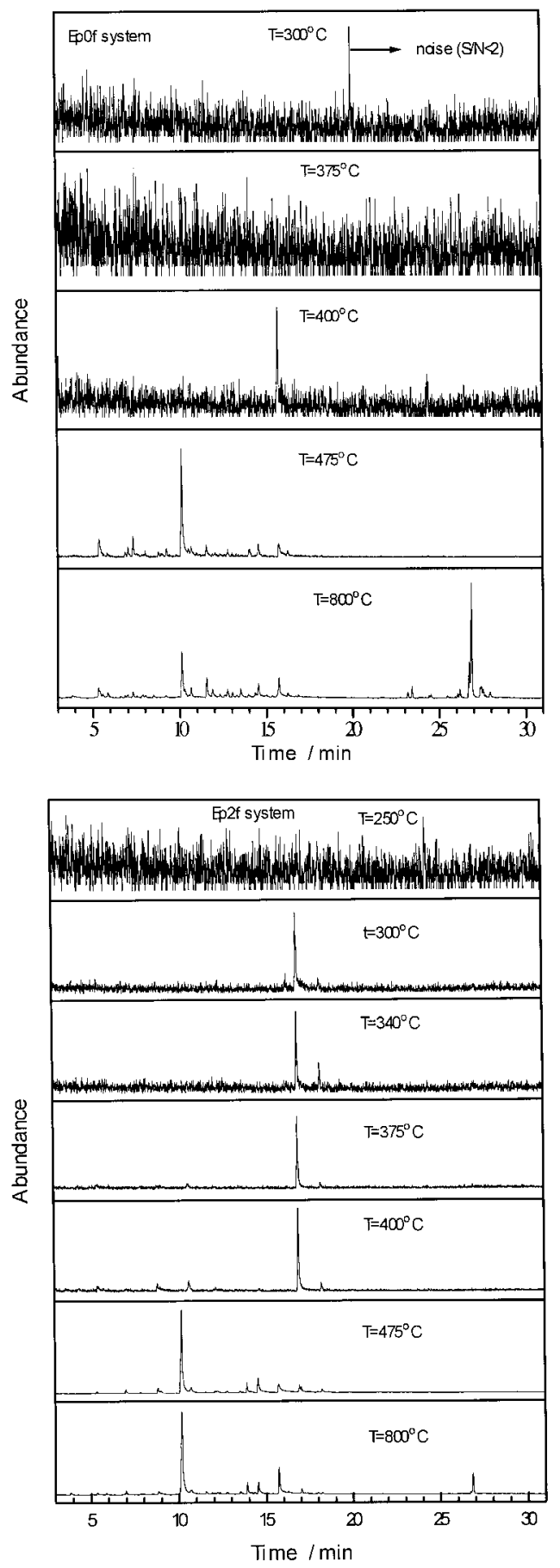

Figure 5 Various pyrolysis GC profiles at different temperature for (a) Ep0f and (b) Ep2f. 
Table III Volatile Products of Thermal Degradation of Epoxy Resin and Its Blends Identified by Mass Spectra and Literature ${ }^{1,11,12}$

\begin{tabular}{|c|c|c|c|}
\hline $\begin{array}{l}\text { Evolved Time } \\
\text { (min) }\end{array}$ & $\begin{array}{c}m / e \\
\text { Value }\end{array}$ & Compound & $\begin{array}{l}\text { Identified } \\
\text { Method }^{\mathrm{b}}\end{array}$ \\
\hline 5.391 & 79 & unidentified & - \\
\hline 6.887 & 93 & pyridine & $\mathrm{L}$ \\
\hline 7.025 & 105 & unidentified & - \\
\hline 8.851 & 108 & $(o, m, p)$-cresol or methoxy benzene & $\mathrm{L}$ \\
\hline 9 & 152 & & $\mathrm{P}$ \\
\hline 10.115 & 108 & $(o, m, p)$-cresol or methoxy benzene & $\mathrm{L}$ \\
\hline 10.125 & 108 & $(o, m, p)$-cresol or methoxy benzene & $\mathrm{L}$ \\
\hline 10.184 & 94 & Phenol & $\mathrm{L}$ \\
\hline 10.632 & 119 & & $\mathrm{P}$ \\
\hline 10.646 & 122 & $(o, m, p)$-ethyl phenol or ethoxy benzene or dimethyl phenol ${ }^{\mathrm{a}}$ & \\
\hline 11.536 & 122 & $(o, m, p)$-ethyl phenol or ethoxy benzene or dimethyl phenol ${ }^{a}$ & $\mathrm{~L}$ \\
\hline 11.876 & 108 & $(o, m, p)$-cresol or methoxy benzene & $\mathrm{L}$ \\
\hline 12.058 & 136 & $(o, m, p)$-isopropyl phenol & $\mathrm{L}$ \\
\hline 12.727 & 132 & & $\mathrm{P}$ \\
\hline 13.015 & 136 & $(o, m, p)$-isopropyl phenol & $\mathrm{L}$ \\
\hline 13.054 & 146 & & $\mathrm{P}$ \\
\hline 14.553 & 136 & $(o, m, p)$-isopropyl phenol & $\mathrm{L}$ \\
\hline 15.745 & 134 & & $\mathrm{~L}$ \\
\hline 16.922 & 183 & unidentified & - \\
\hline 23.178 & 196 & & $\mathrm{~L}$ \\
\hline 23.414 & 213 & & $\mathrm{P}$ \\
\hline
\end{tabular}


Table III Continued

\begin{tabular}{|c|c|c|c|}
\hline $\begin{array}{l}\text { Evolved Time } \\
\quad(\min )\end{array}$ & $\begin{array}{c}m / e \\
\text { Value }\end{array}$ & Compound & $\begin{array}{l}\text { Identified } \\
\text { Method }^{\text {b }}\end{array}$ \\
\hline 26.056 & 237 & & $\mathrm{P}$ \\
\hline 26.727 & 212 & & $\mathrm{P}$ \\
\hline 26.858 & 228 & & $\mathrm{~L}$ \\
\hline 27.527 & 252 & & $\mathrm{P}$ \\
\hline 27.932 & 270 & & $\mathrm{P}$ \\
\hline
\end{tabular}

${ }^{a}$ Represent the existence of various substituted position of benzene ring.

${ }^{\mathrm{b}}$ L: library searching; P: proposed by literature.

nitrogen quench; (ii) products with boiling point between liquid nitrogen temperature and room temperature, which was the gas state at room temperature and the liquid state under liquid nitrogen quench; and (iii) products with boiling point higher than room temperature, which was the liquid state at room temperature and under liquid nitrogen quench.

The products type (i) and (ii) were analyzed using a gas chromatograph (GC) (Shimadzu GC14A) equipped with a flame ionization detector (FID) and a packing column (Shimadzu, $15 \mathrm{~m}$ long coated with $\mathrm{Al}_{2} \mathrm{O}_{3} / \mathrm{KCl}$ ), under the following operating parameters: the column injection temperature was $200^{\circ} \mathrm{C}$; the column operated isothermally at $30^{\circ} \mathrm{C}$ for $10 \mathrm{~min}$ and then heated to $180^{\circ} \mathrm{C}$ at the heating rate of $7.5^{\circ} \mathrm{C} / \mathrm{min}$; the carrier gas was nitrogen with a flow pressure of $2 \mathrm{~kg} / \mathrm{cm}^{2}$. The spectra of product type (i) and (ii) were compared with ref. 13.

The products type (iii) were used the similar pyrolysis/GC/MS equipment and the condition to separate and to identify them, but the equipment was without a pyrolyzer.

\section{Analysis of Residual Char Yield}

The residual char yields after TGA analysis were pressed into pellets with potassium bromide and studied using Fourier transform infrared spectrometer. Additionally, elemental analysis of the residual char yield was also done using elemental analyzer (F002 Heraeus CHN-O Rapid Elemental Analyzer) to determine carbon, hydrogen, oxygen, and nitrogen content.

\section{RESULTS AND DISCUSSION}

\section{Thermal Degradation of Epoxy Blends}

In Figure 2 thermogravimetric (TG) curves (residual weight fraction vs. temperature) and the corresponding thermogravimetric DTG curves (mass loss rate vs. temperature) for FR and epoxy blends were shown. In Table II some characteristics of these curves were listed. In our previous study ${ }^{3}$ the thermal degradation of FR could be divided into three stages. The evolved gas in the first and second stage was predominantly pro- 


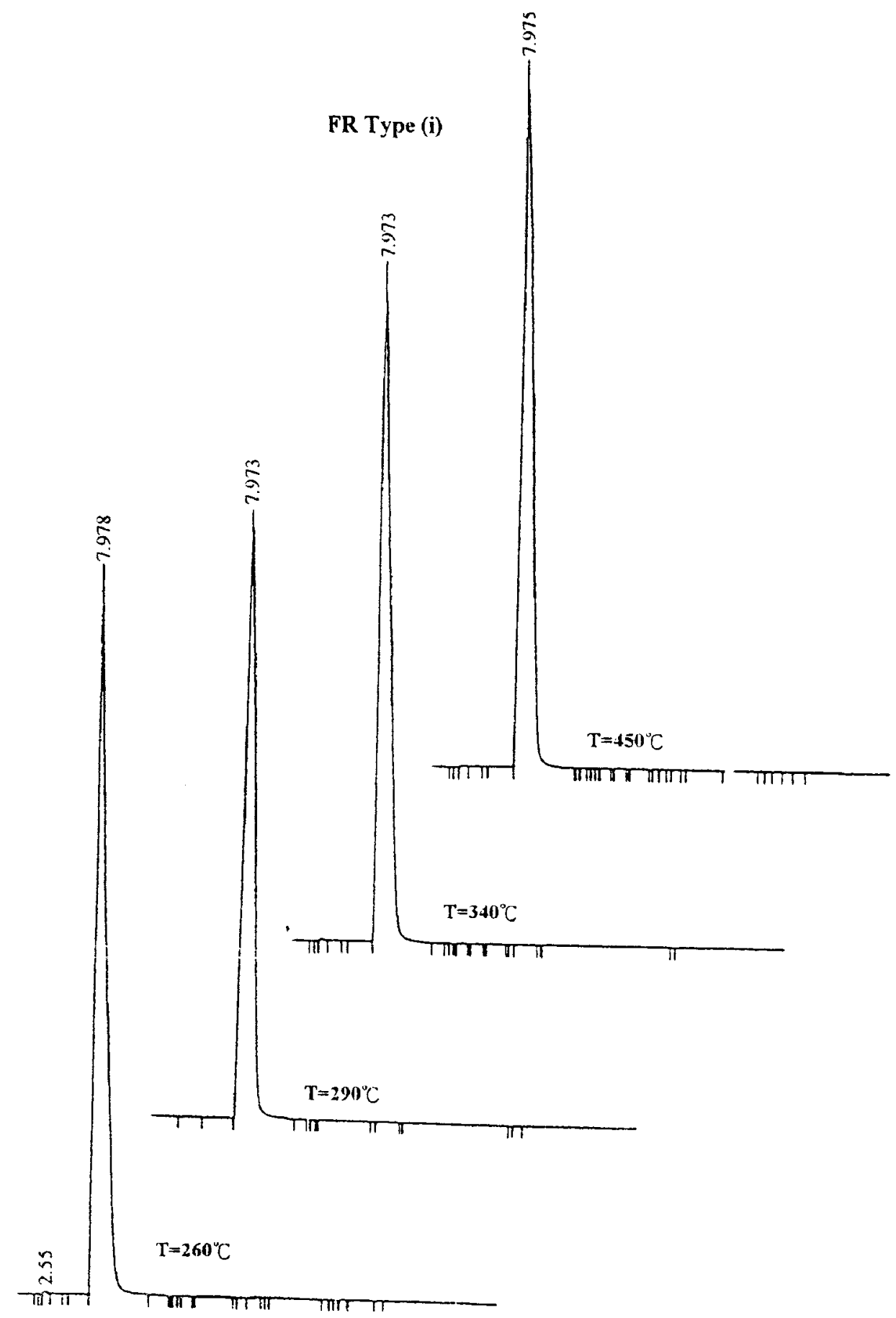

Figure 6 The GC profile of evolved-gases of product type (i) at different degradation temperatures for FR.

pylene. In addition, the FTIR spectra of the condensed phase at various temperature [Fig. 4(a)] indicate an isomerization reaction that occurred during the thermal degradation forming a more thermally stable structure, in which the $\mathrm{P}=\mathrm{N}$ bond changed into a $\mathrm{P}-\mathrm{N}$ bond. ${ }^{14,15}$
The thermal degradation behavior of epoxy and its blends are one stage reaction. The temperature at which $5 \%$ mass is lost $\left(T_{5 \%}\right)$ and the peak temperature $\left(T_{d, \max }\right)$ at maximal degradation rate on DTG curve are lower for epoxy blends than for pure epoxy (Table II). By increasing FR 
content the residual char yield of epoxy blends at $550^{\circ} \mathrm{C}$ increases also, but simultaneously the temperature $\left(T_{d, \max }\right)$ and maximal degradation rate of blends decrease.

\section{Analysis of Evolved Gas}

\section{Analysis by TGA/FTIR}

TGA/FTIR was used to characterize the pyrolysis gas of epoxy and its blends as shown in Figures 3 and 4. As shown in Figure 4(a), the FTIR spectrograms of the gas products of Ep0f at different degradation times (or temperatures) were similar. The major gas product at 38.0 min [Fig. 3(a)] is bisphenol A. The TGA/FTIR results of Ep2f are shown in Figures 3(b) and 4(b). The major gases evolved at 34.9 min were phenol and bisphenol A, identified by the assistance of the spectral databases. Additionally, the different characteristics of the FTIR peaks at various times (or temperatures) between Ep0f and Ep2f were as follows: (1) the intensities of the $\mathrm{CH}_{3}$ and $\mathrm{CH}_{2}$ bond at 2940, 2900, and $2850 \mathrm{~cm}^{-1}$ were scattered by adding of FR, and (2) the intensities of the benzene bond at 1600 and $1500 \mathrm{~cm}^{-1}$ and the ether bond at 1250 and $1180 \mathrm{~cm}^{-1}$ of Ep2f increased with the evolved time.

These results revealed that the addition of phosphorus compounds during the thermal degradation process would easily lead the scission of the $\mathrm{C}-\mathrm{C}$ bond of bisphenol $\mathrm{A}$.

\section{Analysis by Pyrolysis/GC/MS}

The pyrolysis temperatures of epoxy and its blend were determined on the basis of the initial temperatures and inflection points from TG curves. Therefore, the chosen pyrolysis temperatures of Ep0f were $300,375,400,475$, and $800^{\circ} \mathrm{C}$, and for Ep2f were 250, 300, 340, 375, 400, 475, and $800^{\circ} \mathrm{C}$. Figure $5(\mathrm{a})$ and (b) shows the pyrograms of Ep0f and Ep2f at different temperatures. Table III lists the volatile product species produced during the pyrolysis of the investigated samples and identified by their mass spectra and literature. . $^{11,12}$

Figure 5(a) reveals that the peaks of Ep0f pyrograms were scattered within a pyrolysis temperature range of $300-400^{\circ} \mathrm{C}$ and the abundance of the peaks were obvious at above $400^{\circ} \mathrm{C}$. While the major peaks at $10-16$ min were assigned to higher phenol compounds such as $(o, m, p)$ cresols, $(o, m, p)$-isopropyl phenols, and $(o, m$, $p$ )-ethyl phenols, the peaks from 23 to $28 \mathrm{~min}$ were assigned to bisphenol A structure compounds. The bisphenol A structure appeared only at high temperature because bisphenol $\mathrm{A}$, with a boiling point of $360.5^{\circ} \mathrm{C}\left(1.033 \mathrm{~kg} / \mathrm{cm}^{2}\right),{ }^{22}$ was accumulated in the link section between pyrolyzer and GC, and could not be carried out until the higher pyrolysis temperature was reached.

Ep2f pyrograms shown in Figure 5(b) can be divided into two groups: the one with pyrolysis temperature below $400^{\circ} \mathrm{C}$ and the major peak at 16.9-17 min, and the other one with the temperature above $400^{\circ} \mathrm{C}$ and the major peak at $10-11$ min. While the peaks at $10-11$ min were assigned to $(o, m, p)$-ethyl phenol compounds, the compound with the peak at 16.9-17 min and m/e of 183 was unidentified. The peak of bisphenol A appeared at high temperature also, but much smaller than that of EpOf. The major differences of pyrograms between Ep0f and Ep2f were listed as follow: (1) both the scission behavior of the Ep0f and Ep2f systems would be accelerated with the increasing of pyrolysis temperature; (2) the thermal degradation temperature of the epoxy blends would be lower than that of pure epoxy. On the other hand, the addition of FR would accelerate the scission of epoxy resin; and (3) the amount of smaller molecules of the Ep2f system was greater than that of the Ep0f system. This phenomenon was due to FR with the electron withdrawing of the nitrogen atom that could attack and break the bisphenol A structure.

\section{Analysis by Separation/GC/MS}

This part will be focused on the analysis of the evolved gas, especially small molecules, using the separation/GC/MS during the thermal degradation process. Figure 6 shows the pyrograms for product type (i) of FR at different temperatures, while the pyrograms for product type (i) of Ep0f and Ep2f were not observed in these experiments. The spectra of the product type (i) of FR were found to contain a large amount of propylene, and this result correspond to our previous study. ${ }^{3}$

Figure 7(a) to (c) showed a series of GC traces at different temperatures representing product type (ii) gases of FR, Ep0f, and Ep2f, respectively. The product type (ii) gases of Ep0f and Ep2f consisted of mainly $\mathrm{C} 1-\mathrm{C} 4$, saturated, and unsaturated aliphatic hydrogen carbon compounds, and benzene. They were identified by ref. 13 and agreed with Cascaval's study. ${ }^{21}$ Additionally, the amount of the evolved products of FR, Ep0f, and Ep2f all increased with increasing temperature. 
(a) FR Type (ii)

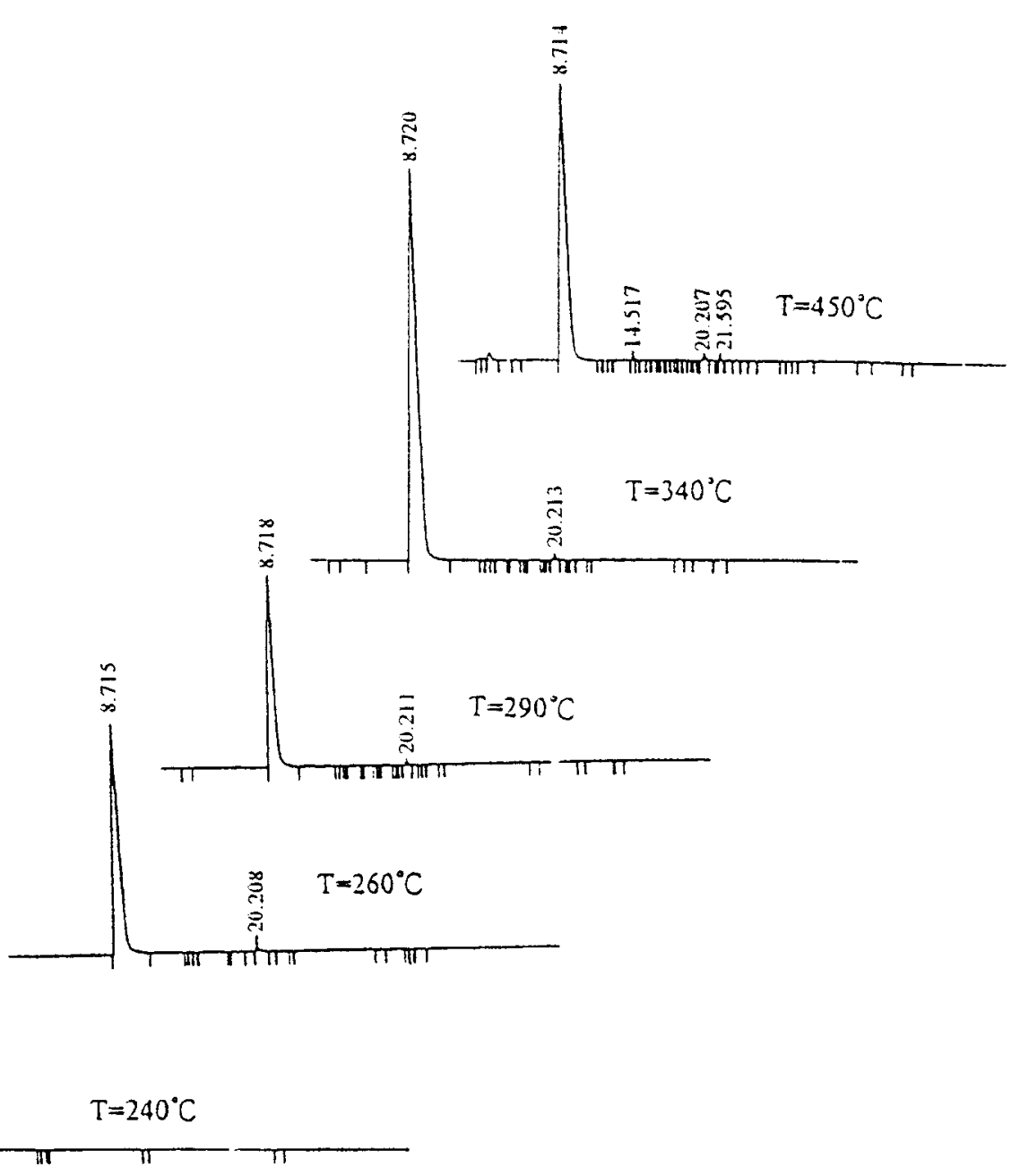

Figure 7 The GC profile of evolved gases of product type (ii) at different degradation temperatures for (a) FR, (b) Ep0f, and (c) Ep2f.

The major difference of the evolved gases product type (ii) between Ep0f and Ep2f was that the evolved product of pure epoxy at 9.3-9.4 and 13.3-14.5 min disappeared by addition of FR, and the new product of the blends at an evolved time of 8.9-9.0 min was produced.

Both Figure 8 and Table IV represented a GC/MS traces of the evolved gas of product type (iii) for FR, Ep0f, and Ep2f when samples were heated to a peak temperature of the DTG curve at the heating rate of $10^{\circ} \mathrm{C} / \mathrm{min}$. The evolved products of FR at various evolved times were identified to be acetone, $N$-propanamine (or dipropyl ether), and tributyl ester phosphoric acid by the spectra data library. The major evolved type (iii) products of EpOf and Ep2f included acetone, 1-propanol, 2-propanol, phenol, $(o, m, p)$-isopropyl phenol, and (o, $m, p)$-isopropylenyl 2,4-cyclohexidenone.

The major differences of evolved type (iii) between Ep0f and Ep2f were stated as follow: (1) The formation of 1-propanol and 2-propanol was only observed during thermal degradation of epoxy by adding of FR. (2) All of the amount of acetone, phenol, and isopropyl phenol produced by Ep2f were greater than those of Ep0f.

The above phenomena was due to FR released propylene during the thermal degradation process, and its residual char contained an active proton to attack the 4,4-isopropyl phenol, ether group, and $\mathrm{C}-\mathrm{N}$ bond. Therefore, phenol, isopropyl phenol, and propyl radicals were produced. 


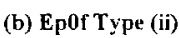
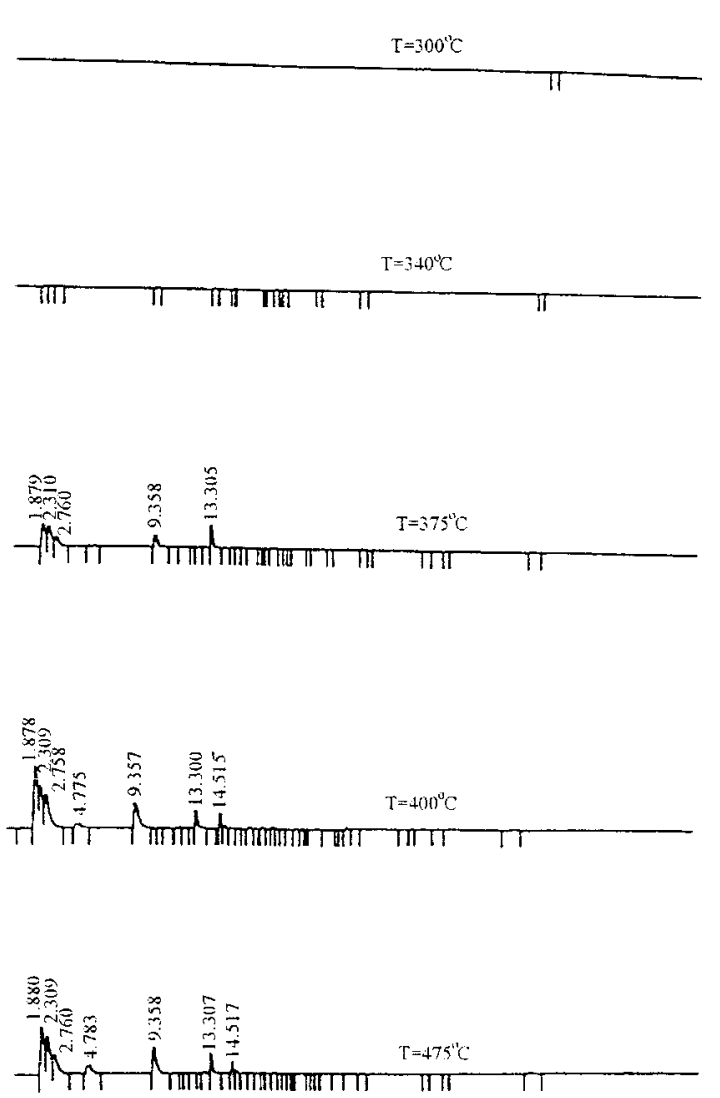

(c) Ep2f Type (ii)
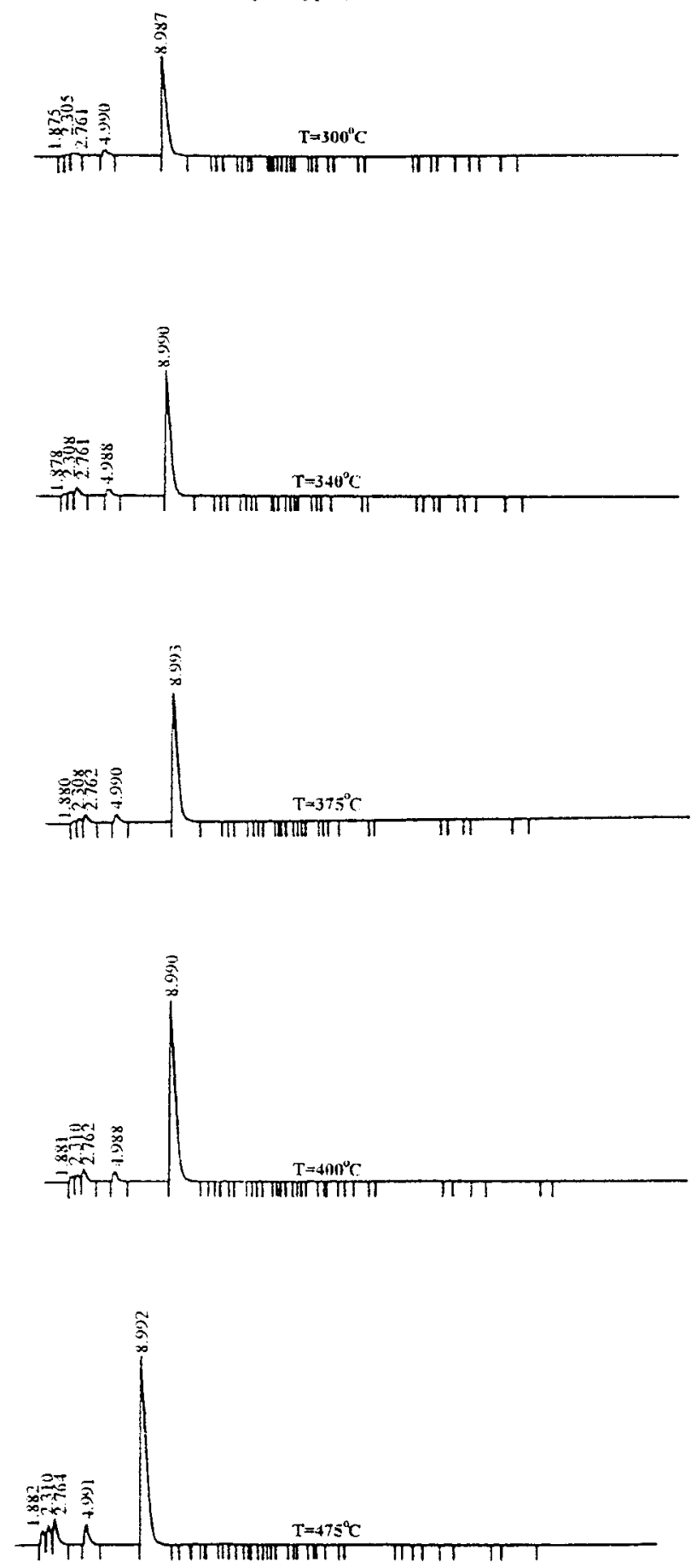

Figure 7 (Continued from the previous page)

The propyl radical reacts then with the residual char to form 1-propanol, 2-propanol, and acetone through many complex reactions. ${ }^{16}$ Additionally, the sources of a large amount of acetone, phenol, and isopropyl phenol were also due to an active proton from FR easily attacked bisphenol A structure.

From the evolved substances in the experiments, our previous study, ${ }^{16}$ and literature, ${ }^{1,11,12}$ the pyrolysis mechanism of pure epoxy resin and 
its blends were proposed to be as follows: (a) pyrolysis mechanism of epoxy resin
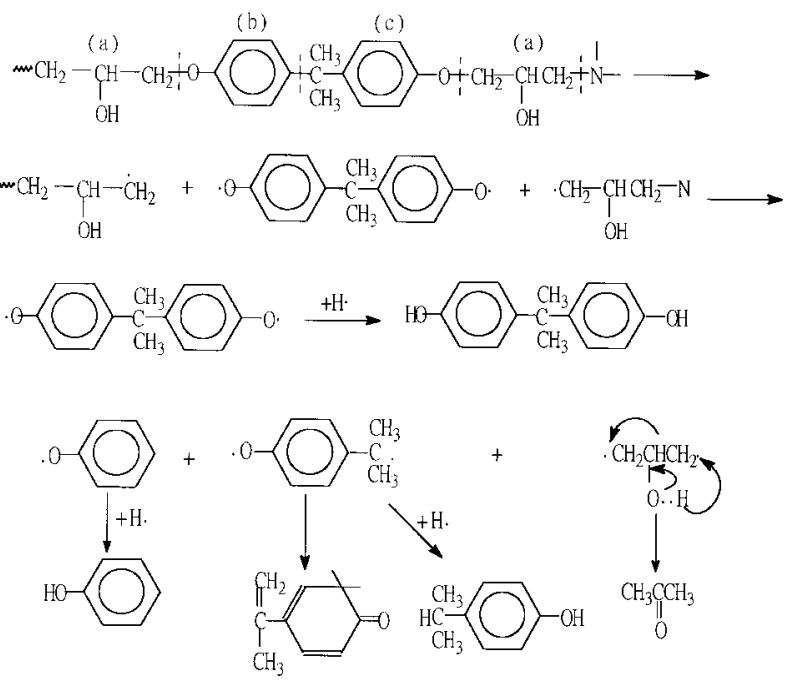

(b) pyrolysis mechanism of epoxy resin blended with FR.
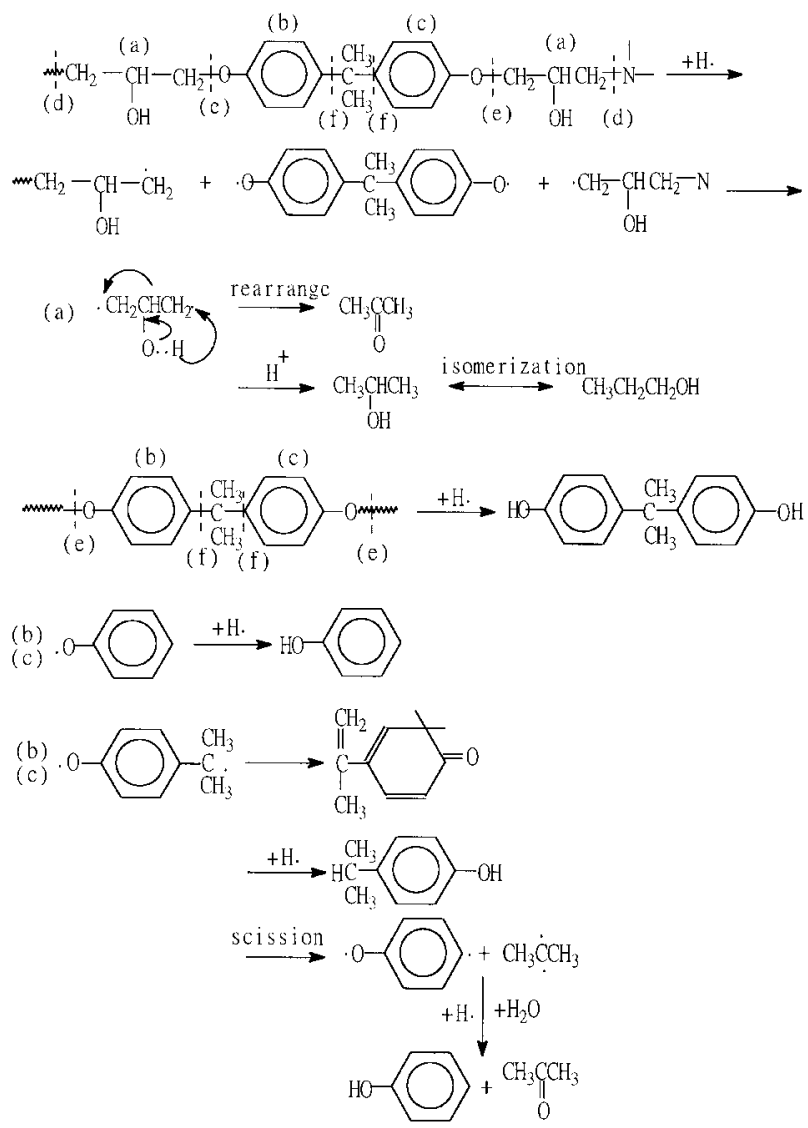

\section{Analysis of Residual Char Yield}

The FTIR spectra of the condensed phase of epoxy and its blends at various temperatures (with a

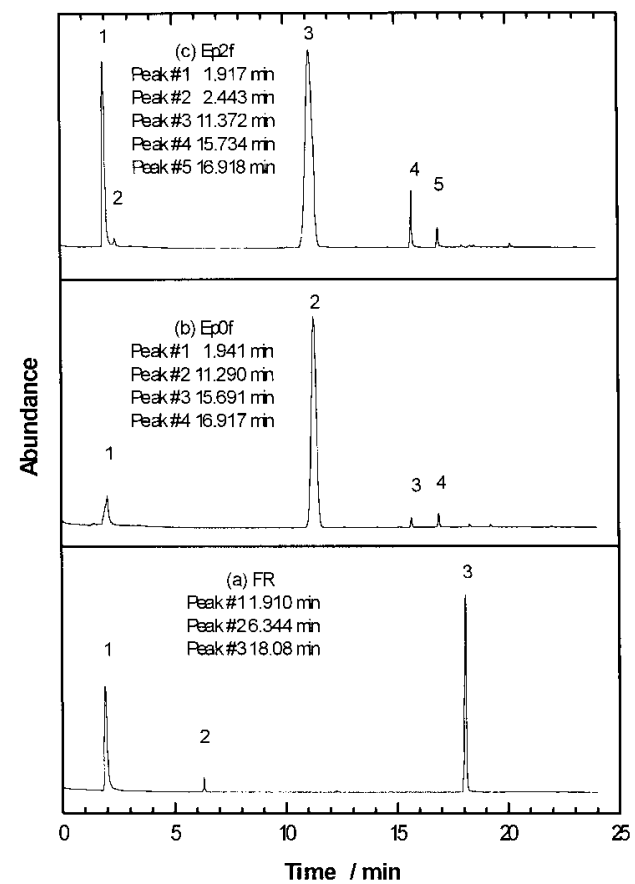

Figure 8 The GC profile of evolved gases of product type (iii) for (a) FR, (b) Ep0f, and (c) Ep2f.

heating rate of $10^{\circ} \mathrm{C} / \mathrm{min}$ under nitrogen atmosphere) were shown in Figure 9(a) and (b), respectively. The intensities of peaks at 1600 and 1500 $\mathrm{cm}^{-1}$, assigned to resulting from benzene ring of Ep0f, decrease with the increase of temperature, as shown in Figure 9(a). Additionally, two of three absorption peaks, one at $1250 \mathrm{~cm}^{-1}$ due to the $\mathrm{Ar}-\mathrm{O}$ group and the other at $1040 \mathrm{~cm}^{-1}$ due to the $\mathrm{C}-\mathrm{O}$ group, disappeared at $550^{\circ} \mathrm{C}$. Finally, the peaks at 2940,2900 , and $2850 \mathrm{~cm}^{-1}$, resulting from methyl and methylene, disappear at $550^{\circ} \mathrm{C}$. But it is worth noticing that the bands at 810 $\mathrm{cm}^{-1}$ due to the out of plane $\mathrm{C}-\mathrm{H}$ bending of the $p$-substituted aromatic ring disappeared at $550^{\circ} \mathrm{C}$, and peaks 9 and 10 due to the out-of-plane $\mathrm{C}-\mathrm{H}$ vibration of honeycomb compounds ${ }^{20,21} \mathrm{de}-$ veloped.

In the FTIR spectra of Ep2f [Fig. 9(b)] it is evident that all of the signals such as Ar-O, $\mathrm{C}-\mathrm{O}$, benzene ring, methyl, and methylene disappeared at $400^{\circ} \mathrm{C}$, and the out-of-plane $\mathrm{C}-\mathrm{H}$ vibration of honeycomb structure became evident and broad. The band broadness may be the result of phosphorus compound bonds such as $\mathrm{P}-\mathrm{O}-$ (C) $\left(830-740 \mathrm{~cm}^{-1}\right),(\mathrm{P})-\mathrm{O}-\mathrm{C}(1050-970$ $\left.\mathrm{cm}^{-1}\right), \mathrm{P}-\mathrm{OH}\left(1040-910 \mathrm{~cm}^{-1}\right)$, and $\mathrm{P}-\mathrm{N}$ $\left(1100-930 \mathrm{~cm}^{-1}\right)$, respectively. From the analysis of evolved gas and the increase of the residual 
Table IV Species of Product Type (iii) of Thermal Degradation of Epoxy Resin and Its Blends Identified by Mass Spectra

\begin{tabular}{|c|c|c|c|}
\hline Sample Code & $\begin{array}{l}\text { Evolved Time } \\
\quad(\min )\end{array}$ & Assignation & $m / e$ \\
\hline \multirow[t]{3}{*}{ FR } & 1.910 & Acetone & 58 \\
\hline & & Dipropyl ether & 102 \\
\hline & 18.08 & Tributyl ether phosphoric acid & 206 \\
\hline \multirow[t]{4}{*}{ Ep0f } & 1.941 & acetone & 58 \\
\hline & 11.290 & phenol & 94 \\
\hline & 15.691 & $(o, m, p)$-isopropyl phenol & 136 \\
\hline & 16.917 & (o, $m, p)$-isopropylene 2,4-cyclohexidenone & 134 \\
\hline \multirow[t]{7}{*}{$\mathrm{EP} 2 \mathrm{~F}$} & 1.917 & acetone & 58 \\
\hline & 2.443 & 1-propanol & 60 \\
\hline & & & or \\
\hline & & 2-propanol & 60 \\
\hline & 11.372 & phenol & 98 \\
\hline & 15.734 & $(o, m, p)$-isopropyl phenol & 136 \\
\hline & 16.918 & $(o, m, p)$-isopropylenyl 2,4-cyclohexidenone & 134 \\
\hline
\end{tabular}

char yield, it seem that the epoxy and its blends are split off and the honeycomb structure forms with the increase of temperature. Additionally, the scission of epoxy and the formation of honeycomb structure are easier when adding the FR than without it. The phosphorus atom remains in the residual char yield of Ep2f.

\section{Elemental Analysis}

To understand the proportion of residual content of various elements relative to the initial state $\left(25^{\circ} \mathrm{C}\right)$, the ratio, $R$, was defined:

$$
R=\frac{\begin{array}{c}
\text { content at any temperature } \\
\text { for element } i) *\left(1 * \alpha_{T}\right)
\end{array}}{\left(\text { content at } 25^{\circ} \mathrm{C} \text { for element } i\right)}
$$

where $\alpha_{T}$ is the weight loss fraction of sample at temperature $T$.

Figure 10 showed the variation of this ratio for various elements relative to the weight loss fraction of Ep0f and Ep2f. It could be seen that the carbon, hydrogen, oxygen, and nitrogen atoms were being lost steadily throughout the heating process, but most of the amount of phosphorus atom remained in the residual char yield. This phenomena was also observed in Weil, ${ }^{18}$ and Li's ${ }^{19}$ studies. FTIR analysis of the residual char in this article also showed that phosphorus could function in the condensed-phase to form char.

\section{The Interaction between Epoxy Resin and FR During Pyrolysis Process}

The above evidences revealed that addition of FR would accelerate the scission of epoxy and form new honeycomb structure compounds. To examine the degree of interaction between epoxy and FR during the thermal degradation of epoxy blends, a mixing rule that assumed no interaction effect, was employed:

$$
W_{\text {blend }}=W_{\mathrm{Ep}} \cdot X_{\mathrm{Ep}}+W_{\mathrm{FR}} \cdot X_{\mathrm{FR}}
$$

where $W_{\text {blend }}$ is the residual weight fraction of epoxy blend at temperature, $T ; W_{\mathrm{EP}}$ and $W_{\mathrm{FR}}$ are the residual weight fractions of pure epoxy resin and of FR at temperature, $T ; X_{\mathrm{Ep}}$ and $X_{\mathrm{FR}}$ are the weight fractions of pure epoxy resin and of FR, respectively. Figure 11 shows the comparison of the experimental TG curves and the TG curves calculated according to the mixing rule. They did not match, because the mixing rule showed a two-stage reaction while the experimental results show a one-stage reaction. In addition, the experimental weight loss fractions are smaller than those calculated for the first stage from the mixing rule, while for the second stage that is opposite. The experimental residual char yield at $550^{\circ} \mathrm{C}$ is higher than the results calculated from mixing rule. Therefore, it can be concluded that the interaction between FR and epoxy does exist 

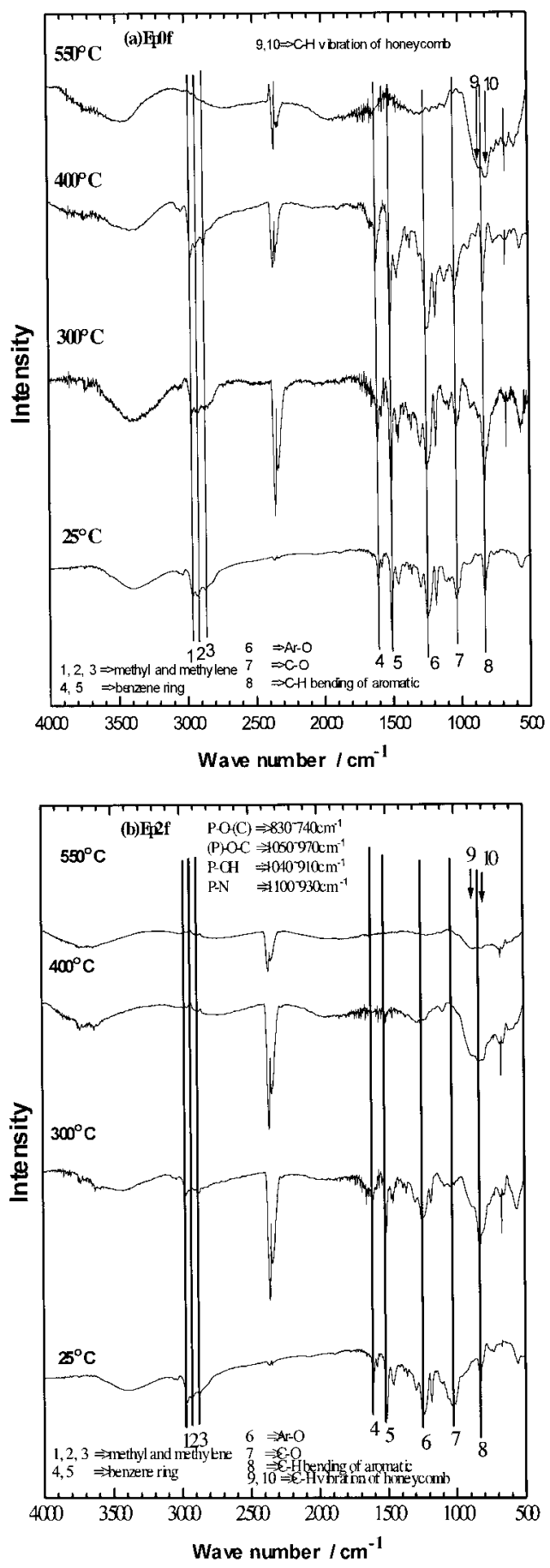

Figure 9 FTIR spectra of condensed phase in thermal degradation at various temperatures for (a) Ep0f and (b) Ep2f.

during the thermal degradation process and corresponds with the above experiments.

\section{CONCLUSION}

From this study, several conclusions could be made:

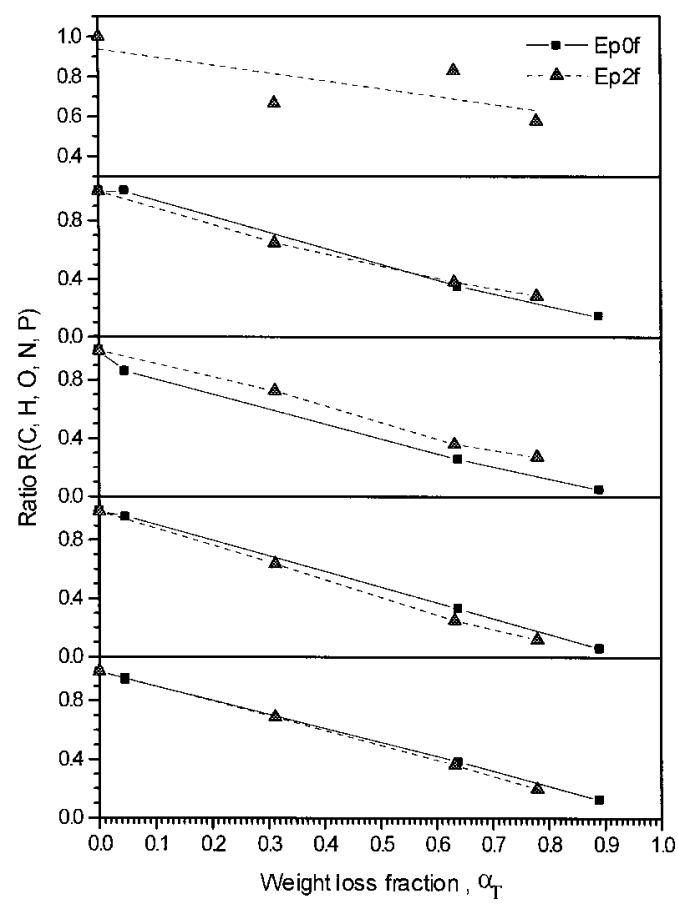

Figure 10 Variation of ratio $\mathrm{R}(\mathrm{C}, \mathrm{H}, \mathrm{O}, \mathrm{N}, \mathrm{P})$ with weight loss fraction $\left(\alpha_{T}\right)$ for Ep0f and Ep2f.

1. The thermal degradation of epoxy resin and its blends was a one-stage reaction.

2. FR reduced the major degradation temper-

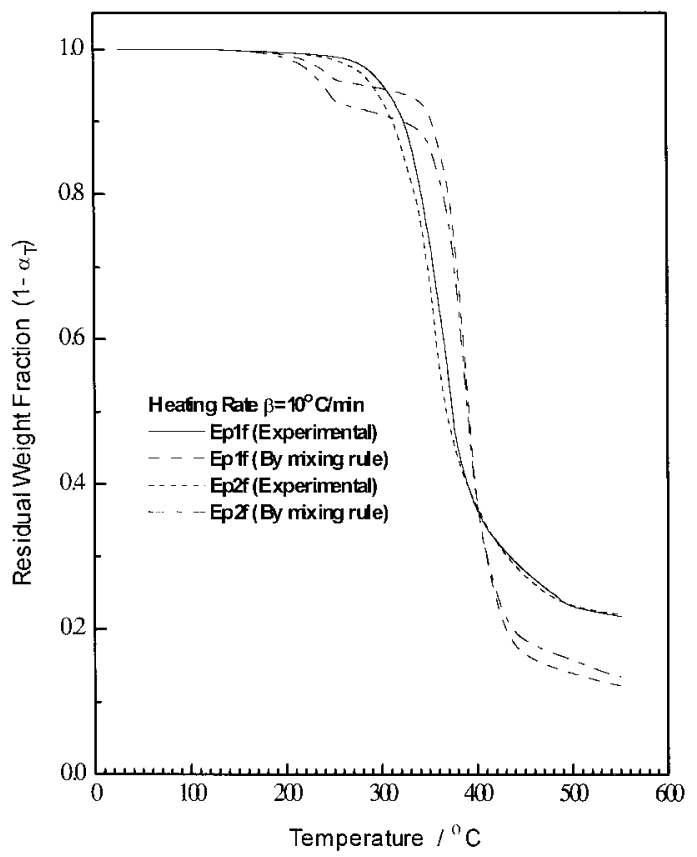

Figure 11 Comparison of experimental TG thermogram and thermogram calculated according to the mixing rule for Ep1f and Ep2f. 
ature of the blends relative to pure epoxy resin, and also accelerated the scission of epoxy resin. There were a large amount of liquid products such as acetone, phenol, and isopropyl phenol that evolved during thermal degradation. Additionally, FR accelerated the formation of carbonaceous char, and thus increased the residual char at $550^{\circ} \mathrm{C}$.

3. The major evolved gas of epoxy resin and its blends formed during the early thermal degradation were bisphenol $\mathrm{A}$ and higher phenol compounds. The bisphenol A originates from the scission of the $\mathrm{C}-\mathrm{O}$ bond of the ether group. By increasing the temperature, the bisphenol A could break into a variety of small molecules such as phenol and isopropyl phenol.

4. The evidences of elemental analysis and infrared spectra of the residual char showed that phosphorus was a residual element, while the other elements mostly diffused to the evolved gas. Additionally, the scission of epoxy and the formation of honeycomb structure are easier by adding the FR than without it.

The authors thank the Chung Shan Institute of Science and Technology (CSIST), Taiwan, R.O.C. for their financial support.

\section{REFERENCES}

1. Grassie, N.; Guy, M. I.; Tennent, N. H. Polym Degrad Stabil 1986, 14, 125.
2. Bellenger, V.; Fontaine, E.; Fleshmann, A.; Saporito, J.; Verdu, J. Polym Degrad Stabil 1984, 9, 195.

3. Denq, B. L.; Hu, Y. S.; Chiu, W. Y.; Chen, L. W. Polym Degrad Stabil 1997, 57, 269.

4. Denq, B. L.; Chiu, W. Y.; Chen, L. W.; Wu, T. R. Polym Degrad Stabil 1997, 57, 261.

5. Denq, B. L.; Chiu, W. Y.; Lin, K. F. J Appl Polym Sci 1997, 66, 1855.

6. Cullis, C. F. The Combustion of Organic Polymers; Oxford: Clarendon, 1981.

7. Petreus, O.; Popescu, F. N.; Cascaval, C. N. Angew Makromol Chem 1994, 222, 13.

8. Denq, B. L.; Hu, Y. S.; Chiu, W. Y.; Chen, L. W.; Chiu, Y. S. J Appl Polym Sci 1999, 74, 229.

9. Smith, I. T. Polymer 1961, 2, 95.

10. Tomson, M. B.; Barone, J. P.; Nancollars, G. H. Atomic Absorpt Newslett 1977, 16, 117.

11. Grassie, N.; Guy, M. I.; Tennent, N. H. Polym Degrad Stabil 1985, 12, 65.

12. Grassie, N.; Guy, M. I.; Tennent, N. H. Polym Degrad Stabil 1985, 13, 11.

13. Lin, C. T. Master Thesis, National Taiwan University, 1992.

14. Papkov, V. S.; IL'Tma, M. N.; Tur, D. R.; Slonimskii, G. L. Polym Sci USSR 1989, 31, 2509.

15. Maynard, S. J.; Sharp, T. R.; Haw, J. F. Macromolecules 1991, 24, 2794.

16. Denq, B. L. Ph. D Thesis, National Taiwan University, 1997.

17. Cascaval, C. N. Eur Polym J 1994, 30, 969.

18. Weil, E. D. Flame Retardancy of Polymeric Materials; Kuryla, W. C.; Papa, A. V., Eds.; Marcel Dekker, New York, 1976, p. 123.

19. Li, J. Z.; Chen, S. Y. J Appl Polym Sci 1990, 40, 417.

20. Socrates, G. Infrared Characteristic Group Frequencies; New York: Wiley, 1980.

21. Factor, A.; Carnahan, J. C.; Dorn, S. B.; Van Dort, P. C. Polym Degrad Stabil 1994, 45, 127.

22. Jordan, T. E. Vapor Pressure of Organic Compounds; Interscience Publishers, New York, 1954. 